\begin{tabular}{c|c|c} 
Issues in & $\begin{array}{c}\text { Informing Science }+ \\
\text { Information Technology SCEN }\end{array}$ & $\begin{array}{l}\text { An Official Publication } \\
\text { of the Informing Science Institute } \\
\text { InformingScience.org }\end{array}$ \\
\hline IISTITUTE & IISIT.org
\end{tabular}

Volume 18, 2021

\title{
TECHNOLOGIES FOR TEACHING IN AN ONLINE ENVIRONMENT
}

\begin{tabular}{lll}
\hline Christina Ellis & $\begin{array}{l}\text { Sam Houston State University, } \\
\text { Huntsville, Texas, United States }\end{array}$ & cellis@,shsu.edu \\
Mae Lane & Sam Houston State University, & mal024@,shsu.edu \\
& Huntsville, Texas, United States & \\
Tori Hollas & Sam Houston State University, & torihollas@shsu.edu \\
& Huntsville, Texas, United State & \\
Jaime Coyne* & Sam Houston State University, & jlb110@shsu.edu \\
& Huntsville, Texas, United States & \\
* Corresponding author & &
\end{tabular}

\section{ABSTRACT}
Aim/Purpose
The authors provide different technology applications useful in online in- struction in addition to providing effective strategies for use in a virtual envi- ronment.

Background

Last year, educators were forced to move their instruction online almost overnight. Many were not prepared to teach effectively in a virtual environment.

Contribution

This paper serves as a resource to educators who are unfamiliar with teaching online as well as for those who would like to enhance their current practice.

Recommendations for Practitioners

Be flexible when teaching in a virtual environment. Remain open to using new and unfamiliar technologies. Be consistent in providing feedback to students and communicate frequently with them.

Impact on Society The abrupt transition for educators, as well as for most workplaces, to an exclusively online environment in response to COVID has long-lasting effects in how business as usual will be conducted. Being proficient and comfortable in navigating a virtual environment is essential.

Future Research As we continue to work virtually, ongoing research that informs our practice is critical for remaining effective educators. Additionally, it is important to remain knowledgeable about current and new technologies available to us.

Keywords online instruction, technology applications, strategies

Accepted by Editor Eli Cohen | Received: February 4, 2021 | Revised: May 5, 2021 | Accepted: June 1, 2021.

Cite as: Ellis, C., Lane, M., Hollas, T., \& \& Coyne, J. (2021). Technologies for teaching in an online environment. Issues in Informing Science and Information Technology, 18, 31-39. https://doi.org/10.28945/4798

(CC BY-NC 4.0) This article is licensed to you under a Creative Commons Attribution-NonCommercial 4.0 International License. When you copy and redistribute this paper in full or in part, you need to provide proper attribution to it to ensure that others can later locate this work (and to ensure that others do not accuse you of plagiarism). You may (and we encourage you to) adapt, remix, transform, and build upon the material for any non-commercial purposes. This license does not permit you to use this material for commercial purposes. 


\section{BACKGROUND}

In early spring of 2020, educators were forced to move their instruction from in-person to online almost overnight. Many were unprepared to teach in a virtual environment and faced having to quickly become proficient in navigating the technology needed for teaching their students virtually. Teachers in K-12 schools, as well as those in higher education, were faced with a steep learning curve and had to work quickly to make this shift.

While instructors were making this transition, K-12 school districts and higher education campuses were struggling to provide training and support to help make this transition as smooth as possible. In addition to supporting instructors, they also worked to ensure their students had the necessary devices and internet access in order to attend their online classes. Educators worldwide experienced an unprecedented situation. As higher education instructors, the authors experienced this firsthand and would like to share strategies and some helpful technologies that could benefit others in the same predicament.

\section{BE FLEXIBLE}

One important factor in being responsive to students, particularly during a stressful period like the Pandemic, is to be as flexible as possible within your courses. During this unprecedented time, students may be managing any number of stressors, such as financial problems or health concerns, and enforcing rigid deadlines for assignments may increase their anxiety. Once a student has missed one or two deadlines that result in grades of a zero, they may become so discouraged about the inability to earn a passing grade, they will likely stop participating in the class. Fluid due dates for assignments is one way to promote students' successful participation (Hanewicz et al., 2017). If given the opportunity to complete assignments with flexibility or as they can within the semester, students will be more inclined to continue to engage in the course. Encourage them to adhere as closely as possible with the original course calendar but be mindful of how you respond when students need additional time to submit their work.

Another way to be flexible within your courses is to build opportunities for student choice regarding how they demonstrate their learning. Allowing students to have some control over their learning has been associated with a positive outcome and enhanced satisfaction with the course itself (Weimer, 2013). Providing options within assignments, such as giving students two or more choices between assignments that are available simultaneously, also has a positive impact on student engagement and exam scores (Hanewicz, et al., 2017). In addition, the instructor is more likely to meet diverse learners' needs through offering choices.

Flexible assessment also provides students with some control and choice over their learning. There are a variety of strategies for including this approach in your courses. For example, you could have students choose which assessments they will complete and the value of those assessments in determining their final grades, within limits given by the instructor (Rideout, 2018). Another method is to offer a few different options regarding how the final grade will be calculated, and the instructor uses whichever option results in the highest grade (Cook, 2001). A third approach is to provide students with different values for each assignment at the start of the course; students are able to choose the value of each assignment at the beginning of the semester. They are required to provide to the instructor, in writing, the justification for their choices (Vander Schee, 2011). Each of these approaches gives students the opportunity to work to their strengths, and it gives them more control over their learning.

Finally, giving students a chance to revise and resubmit assignments when they earn a low score is an effective method for ensuring mastery of the content. Particularly when a class is online, there is potential for students to misunderstand the directions given for an assignment. An opportunity for 
students to make corrections based on instructor feedback and then submit the assignment again for a potentially higher grade works to ensure student understanding.

Due to the uncertainty (job loss, new employment, etc.) brought on by the Pandemic, many students are balancing their workload with school. One way to help students is to provide opportunities for your class to be asynchronous. This provides students with flexibility to work on the modules and assignments on their own time around their work schedules and family life. In fact, because of the Pandemic, Severino et al., (2021) created a six-week virtual learning opportunity for Prekindergarten to second grade students to help aide in the academic learning gaps that resulted during the Spring 2020 semester. Offering an asynchronous format afforded working parents to work around their schedule to help their students in participating in this virtual learning environment.

In addition, many instructors use this type of asynchronous instruction during their flipped classrooms in which students complete modules and assignments that review key concepts prior to class and have an opportunity to then apply it when in the classroom (Al Mulhim, 2021; Alvarado, 2020; Rehman \& Fatima, 2021). We realize that asynchronous instruction may not be possible during the whole semester but providing those opportunities can be advantageous to your students' performance and attitude toward the class, especially in uncertain times (such as the Pandemic).

\section{USE CURRENT TECHNOLOGIES}

Incorporating the use of current technologies is another effective way to enhance your online class. Many higher education institutions have platforms such as Blackboard or Canvas for their online classes. More frequently instructors are incorporating additional applications in their classes for a variety of reasons, including for assessment, engagement, and personalization. As instructors, start small by incorporating one or two applications that you feel the most comfortable in incorporating in your classroom. For teacher educators, using technology applications also provides an opportunity for your students to learn effective tools for the K-12 classroom. Our students have shared that they enjoyed the incorporation of technology applications because they felt it was a great way to engage and even learn more about useful tools. In addition, technology lends itself to constructivist learning in which students construct their own learning through hands-on experiences (Barak, 2017). We have shared the following technology applications that can be incorporated in an online or even hybrid classroom environment.

\section{FLIPGRID}

We have used this application in many of our online classes. Flipgrid (https://info.flipgrid.com) is a great tool for engaging students in discussion. It is a great alternative to using discussion boards in the more common platforms such as Blackboard, for example. Students and instructors can submit discussion posts through text or videos and classmates can respond. There are also settings available through which instructors can approve the posts (this is optional). Students find this application engaging because they can be more creative in their discussion posts, and it is also more aesthetic to users. One example that we used in one of our teacher education classes was on the topic of formative assessment. We posted the prompt "Share one way you can use formative assessment in your classroom." Students responded using a video response, and they also responded to other classmates' responses. As instructors, we assessed their knowledge of this topic, and the students also had an opportunity to learn from each other.

\section{PODCASTS}

Podcasts are becoming increasingly more popular. Perhaps, its accessibility has attracted students, specifically younger generations. Students can listen to podcasts anywhere and everywhere. Instructors and students can even create their own podcasts. Some instructors have had students create podcasts for assignments, either as an individual or group. In addition, podcasts are available on a wide 
variety of topics. As an instructor, you can also review the podcast through reading the transcript if you are limited on time and want to include it in your class.

\section{PLICKERS}

Prior to the Pandemic, we have used Plickers (https://help.plickers.com/hc/en-us) in our face-toface classes as an assessment tool. It was a quick way to assess students on their knowledge and also a great way to take attendance for the class time period. The neat feature of Plickers is that you can use the questions for multiple classes. First, you create "classes" with your students' names. Then you print out Plicker cards. Each card is assigned to a student using a QR code. Then create one set of questions to use for your classes. While in class, you can show the students the questions, and they use the Plicker cards to reveal their answer. It creates a chart of your students' mastery of the questions. We were pleasantly surprised that you can actually use Plickers in a remote learning format. Using this application online via Zoom, the teachers reveal the question, and the students can answer it in real-time providing the teacher immediate feedback on the students' mastery of the topic. The beauty of this application is that is it great for hybrid classes in which instructors can use this for their face-to-face classes and for their online classes (Zoom).

\section{FLIPPITY}

Flippity (https://www.flippity.net) is a great resource for instructors because included in this application are a variety of Google sheet templates that instructors can use to make engaging and interactive games such as Jeopardy, word searches, board games, and Bingo. Useful videos are also available on how to incorporate this application in your class, which can be tailored to your content area. This type of application would be useful to those who are teaching via Zoom or have some type of synchronous class time. We have used this resource for social gatherings via Zoom. It can break the monotony of meetings and help engage participants.

\section{$S W I V L$}

We have incorporated SWIVL devices (https://www.swivl.com) in our work with our first-year residents. These technological devices are robotic in nature that comes with a mount for phones/iPads, markers for teachers to wear and a remote control. While wearing a marker around their neck, a teacher can place his or her phone on the SWIVL mount. The SWIVL will follow the teacher while recording his or her instruction. Then the teacher can upload their video to a FERPA (Family Educational Rights and Privacy Act) compliant cloud. Our residents use these videos for personal reflection and even for their EdTPA portfolio. But perhaps the best use is the feedback they receive from their mentors. Mentors are assigned to the student's cloud where they can access and view the student's teaching video; they can then provide valuable feedback on the resident's teaching. In addition, there are other devices available that are very similar to SWIVL. We found it to be a great investment in our work of preparing teachers. McCoy and Lynam (2021) found similar results in their study with pre-service teachers where they used SWIVLs and found it to be a valuable tool for self-reflection.

\section{PEAR DECK}

One of the authors found out about this application tool from a colleague who used this tool on a regular basis with her remote instruction class. Pear Deck (https://www.peardeck.com) is an interactive tool that can increase student engagement by providing activities building on academics, social and emotional learning. It can also be used as a form of assessment, part of a check-in system, and discussion starters. Many instructors use this tool as an add-on to their regular instruction. There are also many videos on how to use this tool and their site features a section "Cool things you can do" (https://help.peardeck.com/en/cool-things-you-can-do) that shares fun and engaging activities to enhance your instruction. 


\section{SOCRATIVE}

Socrative (https://www.socrative.com) is an application that can be used for both K-12 and higher education. Instructors can create quizzes for students and launch them in real time. Instructors are provided instant feedback on their students. One of the authors has been using Socrative for years as an interactive way to engage and formative assess her face-to-face classes. With the shift to virtual learning, many instructors have found innovative ways to incorporate it in their online classes. Christianson (2020) used Socrative to create online polls to check her Chemistry students' understanding of key concepts. In their study with EFL learners in an English class, Alharbi \& Meccawy (2020) found that that traditional paper quizzes were preferred over technology-based assessments, but after being immersed in a study with Socrative quizzes, their attitudes changed. They preferred Socrative over the traditional based assessments.

\section{TED TALKS}

TED Talks (https://www.ted.com/watch/ted-ed) features a variety of informational presentations by renowned speakers and experts over a plethora of topics. TED-Ed videos feature short videos with lessons geared for instructors and students, providing a great way to enhance your lesson or module. Another feature is thought-provoking questions that help the students increase their knowledge base on the featured topic. We have used TED Talks in many of our classes and students enjoy learning from other experts in the field. In addition, TED Talks is continuously updating their library of videos and resources.

Again, we feel that incorporating technology applications has enhanced our classes in a variety of ways. With anything new, start small and build your confidence in using the application. In addition, be clear regarding your expectations in using the type of technology. In their study with undergraduate students, Pechenkina and Aeschiman (2017) found that students tend to use technology in a limited way in their classes. As instructors, model what is expected and how you can use technology to enhance learning. Though technology has become integrated in our daily lives, many students still prefer to use traditional modes of learning (Alharbi \& Meccawy, 2020). Perhaps individuals lean toward what they feel the most comfortable with or have previously used in their earlier learning experiences (K-12 schools). As instructors, we have to model and clearly show students how to use technology for learning.

\section{USING TECHNOLOGY FOR SIMULATIONS}

Also with the Pandemic, instructors had to create simulations in specialty areas such as the sciences, education, and even medicine. Prior to the Pandemic, instructors have had much success in creating simulations to help enhance their teaching with positive results from their students. Alkan and Altundag (2015) found that the incorporation of Titrimetric Analysis being conducted with simulations was viewed favorably as a valuable technology tool for chemistry. Ouahi et al. (2020) found similar results with their study with middle school students using educational computer simulation programs to learn middle school physical science by providing hands-on learning for students. Our department prepares teachers, and, due to the Pandemic, it had to find ways to supplement field experience to help prepare them to be classroom teachers. With the use of Zoom, some instructors reached out to $\mathrm{K}-12$ teachers and were able to observe distance learning teaching. Some instructors used videos from professional learning platforms such as the Teaching Channel (https://www.teachingchannel.com). While many argue that real teaching observations that are faceto-face are the best in preparing teachers, our instructors were left with limited options in preparing their students. 


\section{KEEP UPDATED ON THE LATEST TECHNOLOGY}

Along with incorporating technology applications in your classroom instruction, it is also important to keep updated on how to use technology in an effective way that will enhance instruction. Take advantage of workshops offered at your institution. This is a valuable opportunity because they share resources that the institution has subscribed to and has access to for instructional purposes. In addition, with the Pandemic, many videos and webinars have been offered to help teachers increase their knowledge and skills in using technology in the classroom. In addition, there are many websites that feature quick tips in using technology in the classroom to enhance teaching and learning. With the popularity of social media, more and more educators are using blogs to document their teaching and provide effectives teaching tips. The unique feature of blogs is the are usually quick to access and read. Some even include photos and videos along with their teaching tips.

\section{ONLINE CLASSES ARE BECOMING MORE AND MORE POPULAR}

Even prior to the Pandemic, online classes were becoming more and more popular because of the accessibility. There is a demand for online classes worldwide. In fact, many K-12 parents of opted out of traditional in-person schooling and chose virtual schooling for their child to finish their education. Currently, some higher education institutions are experiencing a drop in enrollment due to the uncertainty of the Pandemic. We, as higher educational institutions, need to find ways to appeal to students, and one possibility is the increase of online learning. There is no argument that there is value in face-to-face teaching, but there is an appeal to online learning. Many of our students are balancing one to two jobs, and there is a flexibility online classes provide in which students can work on their own time to complete classes modules and assignments. Coupled with the high cost of education, students are often forced to be employed while attending school. Online courses give them the flexibility to work and attend school in whatever way fits their schedule. We have to embrace this transition as way to increase our student enrollment.

\section{CONSISTENT FEEDBACK AND COMMUNICATION}

Because today's learners are more overwhelmed than ever, it is increasingly important that instructors communicate with their students regularly. We suggest weekly or even daily communication with students in both written and video forms. Students appreciate having expectations clearly spelled out in writing, but they also value seeing you through either synchronous or asynchronous videos. These communications should include an overview of the topics that will be studied that week along with a description of any assignments that need to be turned in. It is also helpful to remind students of upcoming due dates.

Instructors should also provide timely, regular feedback on all assignments. At the beginning of each course, the instructors should establish a timeframe in which students can expect to receive feedback on their work (Institute for Higher Education Policy, 2000). We recommend that feedback be given within one week of an assignment being submitted. However, the sooner the student receives the feedback, the more likely the feedback will result in student growth. By receiving feedback in close proximity to submitting an assignment, students are able to direct their attention to areas in which they need to grow before submitting the next assignment (Angelo, 1993). Students should also be given multiple opportunities to demonstrate their learning and receive feedback at regular intervals throughout the course so that they can continuously assess their own learning.

Hosting virtual help sessions or office hours also provides a connection to students. In online environments, creating relationships with students can be difficult, but synchronous question and answer sessions can help instructors and students replicate some of the benefits of a face-to-face environment such as the ability for all students to hear the answers to questions. These sessions also serve as a space for students to support one another and to allow the instructor to informally identify gaps in learning that should be addressed. 


\section{CONCLUSION}

This past year has presented educators with many extraordinary and difficult challenges. In responding to those challenges, instructors continue to remain focused on how to best support and keep students engaged in their courses while facing a steep learning curve themelves. While the purpose of this article was to share some of the strategies and tips we used with our courses, they are also beneficial to students under normal circumstances. Being flexible and allowing your students to have some control of their learning provides them with a sense of ownership; in addition, this motivates them to remain engaged and addresses the needs of diverse learners. Additionally, using a variety of current technology in our courses not only enhances engagement but also better prepares our students by helping them to learn more about how to these useful tools in an educational setting. Finally, clear and consistent communication with students regarding our expectations and providing them with timely feedback on assignments are essential to our students' academic success.

\section{REFERENCES}

Alharbi, A. S., \& Meccawy, Z. (2020). Introducing Socrative as a tool for formative assessment in Saudi EFL Classrooms. Arab World English Journal, 11(3), 372-384. https://doi.org/10.24093/awej/vol11no3.23

Al Mulhim, E. (2021). Flipped learning: Self-regulated learning and learning retention of students with inter$\mathrm{nal} /$ external locus of control. International Journal of Instruction, 14(1), 827-846. https://doi.org/10.29333/iji.2021.14150a

Alkan, F., \& Altundag, C. K. (2015). The role of technology in science teaching activities: Web based teaching applications. Journal for the Education of Gifted Young Scientists, 3(2), 1-7. https://doi.org/10.17478/jegys.2015213531

Alvarado, M., Basinger, B., Lahijanian, B., \& Alvarado, D. (2020). Teaching simulation to Generation Z engineering students: Lessons learned from a flipped classroom pilot study, 2020 Winter Simulation Conference (WSC), 2020, pp. 3248-3259. https://doi.org/10.1109/wsc48552.2020.9383950

Angelo, T. A. (1993, April). A 'teacher's dozen: Fourteen general, research-based principles for improving higher learning in our classrooms. AAHE Bulletin, 3-13.

Barak, M. (2017). Cloud pedagogy: Utilizing web-based technologies for the promotion of social constructivist learning in science teacher preparation courses. Journal of Science Education and Technology, 26, 459-469. https://doi.org/10.1007/s10956-017-9691-3

Christianson, A. (2020). Using Socrative online polls for active learning in the remote classroom. Journal of Chemical Education., 97(9), 2701-2705. https://doi.org/10.1021/acs.jchemed.0c00737

Cook, A. (2001). Assessing the use of flexible assessment. Assessment and Evaluation in Higher Education, 26(6), 539-549. https://doi.org/10.1080/02602930120093878

Hanewicz, C., Platt, A., \& Arendt, A. (2017). Creating a learner-centered teaching environment using student choice in assignments. Distance Education, 38(3), 273-287. https://doi.org/10.1080/01587919.2017.1369349.

Institute for Higher Education Policy. (2000). Quality on the line: Benchmarks for success in Internet-based distance education. https://www.ihep.org/publication/quality-on-the-line-benchmarks-for-success-in-internet-based-distance-education/

McCoy, S., \& Lynam, A. (2021). Video-based self-reflection among pre-service teachers in Ireland: A qualitative study. Education and Information Technologies, 26, 921-944. https://doi.org/10.1007/s10639-020-10299-w

Ouahi, M. B., Hou, M. A., Bliya, A., Hassouni, T., \& Ibahmi, E. M., (2021). The effect of using computer simulation on students' performance in teaching and learning physics: Are there any gender and area gaps? Education Research International, Article ID 6646017. https://doi.org/10.1155/2021/6646017

Pechnenikna, E. \& Aeschliman, C. (2017). What do students want? Making sense of student preferences in technology-enhanced learning. Contemporary Educational Technology, 8(1), 26-39.

https://doi.org/10.30935/cedtech/6185 
Technologies for Teaching in an Online Environment

Rehman, R., \& Fatima, S. S. (2021). An innovation in flipped classroom: A teaching model to facilitate synchronous and asynchronous learning during a pandemic. Pakistan Journal of Medical Sciences, 37(1), 131-136. https://doi.org/10.12669/pjms.37.1.3096

Rideout, C. (2018). Students' choices and achievement in large undergraduate classes using a novel flexible assessment approach. Assessment \& Evaluation in Higher Education, 43(1), 68-78. https://doi.org/10.1080/02602938.2017.1294144

Serevino, L., Petrovich, M., Mercanti-Anthony, S., \& Fischer, S. (2021). Using a design thinking approach for an asynchronous learning platform during COVID-19. LAFOR Journal of Education, 9(2), 145-162. https://doi.org/10.22492/ije.9.2.09

Vander Schee, B. A. (2011). Let them decide: Student performance and self-selection of weights distribution. Journal of Education for Business (86), 352-356. https://doi.org/10.1080/08832323.2010.540047

Weimer, M. (2013). Learner-centered teaching: Five key changes to practice (2nd ed.). Wiley.

\section{AUTHORS}

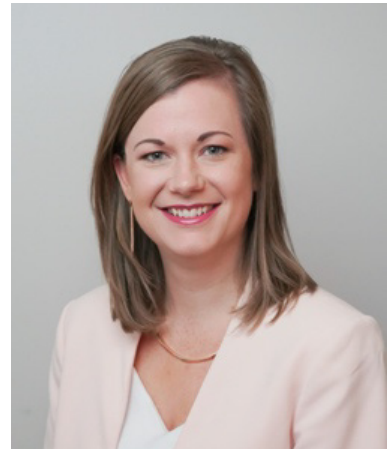

Dr. Christina Ellis is the Director of Accreditation and Accountability Services and the Director of the 4+1 TEACH Program at Sam Houston State University. Prior to joining the university, she served in multiple teaching and administrative roles in K-12 schools. Her research focuses on novice teacher induction, teacher retention, educator job satisfaction, and assessment.

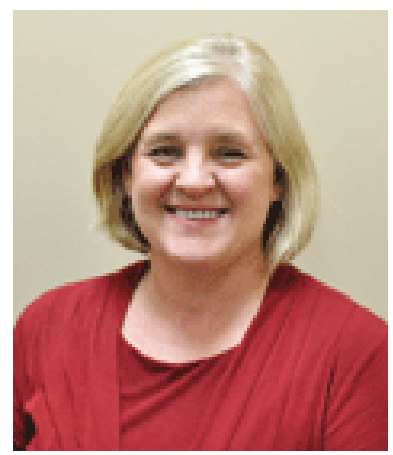

Mae Lane is an Associate Professor in the School of Teaching and Learning at Sam Houston State University. She teaches undergraduate and graduate courses for the College of Education. Her research interests include training pre-service teachers, content area literacy and secondary education. She can be reached at mal024@shsu.edu. 


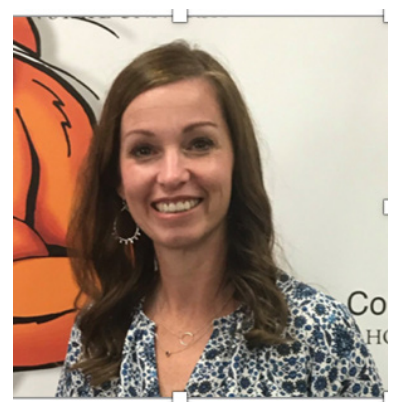

Dr. Tori Hollas is an associate professor in the School of Teaching and Learning at Sam Houston State University in Texas, where she teaches graduate courses in the 4+1 TEACH program. To date, Dr. Hollas's research has focused on novice teacher induction, pre-service and in-service teacher preparation, and the evaluation of teacher candidates. Additional research has focused on the relationship between high-quality feedback and its link to student performance, value-added measures of teacher effectiveness, and the technical properties of several different gauges of teaching quality, including their ability to predict student outcomes.

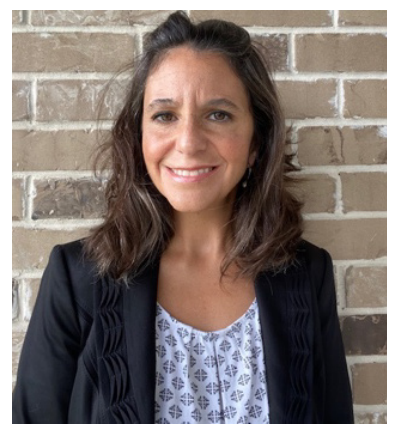

Jaime Coyne is an Associate Professor in the School of Teaching and Learning at Sam Houston State University. She teaches undergraduate and graduate courses for the College of Education. Her research interests includes training pre-service teachers, self-efficacy, content literacy and technology. She can be reached at 11b110@shsu.edu. 